\title{
Influence of SiC Nanoparticle Reinforcement on FSS Welded 6061-T6 Aluminum Alloy
}

\author{
S. Suresh $\mathbb{D},{ }^{1}$ K. Venkatesan $\left(\mathbb{D},{ }^{2}\right.$ and Elango Natarajan $\mathbb{D}^{3}$ \\ ${ }^{1}$ Assistant Professor, Department of Mechanical Engineering, Jayalakshmi Institute of Technology, India \\ ${ }^{2}$ Assistant Professor, Department of Metallurgical Engineering, Government College of Engineering, Salem, India \\ ${ }^{3}$ Faculty of Engineering, UCSI University, Kuala Lumpur, Malaysia
}

Correspondence should be addressed to Elango Natarajan; cad.elango.n@gmail.com

Received 10 June 2018; Revised 24 August 2018; Accepted 19 September 2018; Published 22 November 2018

Academic Editor: Andrew R. Barron

Copyright (C) 2018 S. Suresh et al. This is an open access article distributed under the Creative Commons Attribution License, which permits unrestricted use, distribution, and reproduction in any medium, provided the original work is properly cited.

The current research focuses on the mechanical properties and the microstructural behavior of friction stir spot-welded 6061-T6 aluminum alloy reinforced with $\mathrm{SiC}$ nanoparticles. Weld samples are produced with and without the addition of $\mathrm{SiC}$ nanoparticles to the joint. The microhardness and lap shear strength of the joints are investigated. The cross section of welds and the fracture surfaces are studied by a stereo zoom microscope. Microstructure and distribution of reinforced particles in the stir zone are examined through optical and scanning electron microscopies. It is observed that the reinforcement of SiC nanoparticles significantly influences the grain size and hence the weld properties. The highest hardness of $93 \mathrm{HV}$ and the maximum shear load of $2650.5 \mathrm{~N}$ are observed at the stir zone of the sample with $29 \% \mathrm{SiC}$. All the weld samples exhibit the similar "W" shape hardness profile. From the observed results, the selected set of process parameters is found adequate in order to fabricate sound $\mathrm{Al} / \mathrm{SiC}$ composite joints.

\section{Introduction}

Aluminum alloys attract the industries because of their attributes such as low density, high specific strength, good castability, and excellent thermal conductivity. They are regarded as the most promising candidates to reduce the weight of automobiles in the automotive and other industries $[1,2]$. There are numerous advantages in the 6061-T6 aluminum alloy which include excellent weldability, high mechanical properties, and high strength/weight ratio. In recent years, FSSW, invented by TWI, UK, is being used for welding aluminum alloys and magnesium alloys, which are complicated to weld by the fusion welding process [3]. The FSSW is attributed by the plunging, retracting of the nonconsumable rotating tool with a specified speed rate and short time duration (dwell) between the movements. Consequently, a sort of frictional heat is produced at the interface of the workpiece and the tool, and a solid state bond of a fine-grained microstructure is provided by the plastic deformation between the upper and lower sheets $[4,5]$. It is also used as the superior replacement for the resistance spot-welding process, especially for aluminum and steel for which better mechanical properties and environmental and metallurgical behavioral are achieved $[6,7]$.

The effect of process parameters on the mechanical properties, microstructure, and fatigue behavior during the FSSW of divergent series of aluminum alloys, copper alloys, magnesium alloys, steels, and dissimilar metals were investigated by many researchers [8-13]. Cao et al. [14] and Karthikeyan and Balasubramanian [15] evidenced FSSW on 6061-T6 Al alloy and reported that the rotational speed and plunge depth of the tool are the most significant parameters to achieve high strength weld joints followed by dwell time and plunge rate. Su et al. [16] mentioned that the rotational tool speed and dwelling time influence the generation of frictional heat leading to high weld strength. Lee et al. [17] reported that the pin angle of $5^{\circ}$, dwell time of about 4.5-5.5 seconds, rotational speed of 1000-1200 are optimum FSSW condition for expected defect-free FSSW on AA6061. Venukumar et al. [18-20] studied the effect of different methods of FSSW on aluminum alloy 6061-T6. They attempted a walking FSSW method and suggested that welds obtained at the tool 
rotational speed of $900 \mathrm{rpm}$ have better static shear strength when compared to the conventional FSSW.

The fabrication of metal matrix composites (MMCs) by friction stir processing (FSP) and friction stir welding (FSW) was also investigated [21-25]. Bahrami et al. [21-23] investigated the effects of $\mathrm{SiC}$ nanoparticles on friction stir welded 7075 aluminum alloy joints and reported that the size of particles significantly influences the weld strength and microstructural behavior of the weld joint. Paidar and Sarab [26] reported the addition of $\mathrm{SiC}$ nanoparticles in the superior strength and wear resistance of FSSW of 2024-T3 aluminum alloy. Tebyani and Dehghani [27] used the SiC particles on FSSW of interstitial-free steels to study the microhardness and tensile strength. It is obvious that the addition of nanofillers improves the mechanical properties of the base matrix drastically $[28,29]$. Barmouz et al. [24, 30] investigated the $\mathrm{Cu} / \mathrm{SiC}$ composite fabricated by FSP and reported that the addition of $\mathrm{SiC}$ nanosized particles enhances the wear resistance and hardness of the composite.

In the present research, the different volume fraction of $\mathrm{SiC}$ nanoparticles was used for the reinforcement of the FSS weld joint of 6061-T6 aluminum alloy. The effect of the filler on mechanical strength, fracture behavior, and microstructure of the joints was investigated and presented.

\section{Materials and Methods}

A commercially available 6061-T6 aluminum alloy sheet, supplied by Cluster Trading Corporation, India, was used to prepare the samples of $100 \mathrm{~mm} \times 35 \mathrm{~mm} \times 2 \mathrm{~mm}$ in dimension through electrical discharge machining (EDM). The chemical composition and the mechanical properties of the chosen base metal are shown in Tables 1 and 2. The overlap area of $35 \mathrm{~mm} \times 35 \mathrm{~mm}$ was configured for spot-weld. The $\mathrm{SiC}$ nanoparticles with an average size of $50 \mathrm{~nm}$, supplied by Hongwu International Group Ltd., China, were used for the reinforcement. Transmission electron micrograph (TEM) with EDS analysis of $\mathrm{SiC}$ nanoparticles is shown in Figure 1.

The guide hole diameter of 1.0, 1.5, and $2.0 \mathrm{~mm}$ was drilled to compact $\mathrm{SiC}$ nanoparticles. The volume fractions of the nanoparticles to be compacted in the hole were calculated based on the guide hole diameter and the tool pin dimension. The sample without $\mathrm{SiC}$ reinforcement and samples compacted with $\mathrm{SiC}$ in the volume fraction of 14 , 22 , and $29 \%$, respectively, were prepared for the study. The other welding parameters such as tool rotation speed, dwell time, and shoulder plunge depth were kept constant for all the experiments based on the preliminary tests and the available literatures $[4,5]$. Table 3 shows the welding parameters selected for the study.

The FSS welding was performed in a CNC vertical machining center with a fixture designed to clamp the specimens as shown in Figure 2. A tool made of H13 steel, hardened to 55-60 HRC with a shoulder diameter of $12 \mathrm{~mm}$, pin diameter of $5 \mathrm{~mm}$, and pin length of $2.85 \mathrm{~mm}$, was used for experiments. The dimensions of the weld joint and weld tool are shown in Figure 3.
TABLE 1: Chemical composition (wt. \%) of 6061-T6 aluminum alloy.

\begin{tabular}{lcccccccc}
\hline $\mathrm{Mg}$ & $\mathrm{Si}$ & $\mathrm{Fe}$ & $\mathrm{Cu}$ & $\mathrm{Cr}$ & $\mathrm{Mn}$ & $\mathrm{Ti}$ & $\mathrm{Zn}$ & $\mathrm{Al}$ \\
\hline 0.708 & 0.430 & 0.49 & 0.164 & 0.14 & 0.097 & 0.04 & 0.004 & Remaining \\
\hline
\end{tabular}

TABLE 2: Mechanical properties of 6061-T6 aluminum alloy.

\begin{tabular}{lccc}
\hline $\begin{array}{l}\text { Ultimate tensile } \\
\text { strength (MPa) }\end{array}$ & $\begin{array}{c}\text { Hardness } \\
\text { Vickers (HV) }\end{array}$ & $\begin{array}{c}\text { Modulus of } \\
\text { elasticity }(\mathrm{GPa})\end{array}$ & $\begin{array}{c}\text { Elongation } \\
(\%)\end{array}$ \\
\hline 310 & 107 & 68.9 & 10 \\
\hline
\end{tabular}

The photograph of the weld joint prepared for the mechanical test and microstructural examination is shown in Figure 4(a). The lap shear test was performed on the sample as-welded condition in the computerized universal testing machine (CALPAK) as shown in Figure 4(b). Each sample was initially fixed onto the machine, and the shear load was gradually applied on the sample at the crosshead speed of $0.5 \mathrm{~mm} / \mathrm{minute}$ till the sample fractures. The tests were repeated for five samples in each volume fraction, and the corresponding maximum shear load was recorded. The microhardness of the sample across the different regions (SZ, TMAZ, HAZ, and BM) of the weld was measured by a Vicker's microhardness tester (Wilson 402B) with a load of $100 \mathrm{~g}$ for $10 \mathrm{sec}$. Macro examination of the weld cross section was carried out using a stereo zoom microscope (Radial RSM-9). Microstructural characterization studies were done using the optical microscope (Invertoplan), scanning electron microscope (SEM) (Tescan vega 3sbh), and field emission scanning electron microscope (FESEM) (SIGMA $\mathrm{HV}-$ Carl Zeiss).

\section{Results and Discussions}

3.1. Microhardness Test. The microhardness profile of each specimen is represented in Figure 5. The mean hardness at $\mathrm{SZ}$ of the sample without $\mathrm{SiC}$ is $81.25 \mathrm{HV}$. The mean hardness at SZ of $14 \%, 22 \%$, and $29 \%$ SiC-filled samples are 82.62 HV, 85.92 HV, and 93.27 HV, respectively. The hardness of the SZ increases with increase in the volume fraction of $\mathrm{SiC}$ nanoparticles. However, significant hardness variation was not observed between the volume fraction of $0 \%$ and $14 \%$. This could be due to insufficient quantity of SiC nanoparticles in the joint. The highest value $93 \mathrm{HZ}$ of hardness in the SZ was observed with a volume fraction of $29 \%$. In the Al matrix, as the $\mathrm{SiC}$ nanoparticle is distributed in the harder space, it influences grain size, refinement of grains, and different thermal contraction of the $\mathrm{Al}$ matrix and filler material $[24,25,31]$. Hall-petch relationship states that a higher value of hardness is obtained by the smaller grain size. But the sample with $29 \% \mathrm{SiC}$ yielded the maximum hardness despite of its larger grain size [30]. The hardness was found to be gradually decreasing through TMAZ, HAZ and the hardness profile resembles the shape of "W" [19].

3.2. Lap Shear Test. The photograph of specimens after the tensile lap shear test and the maximum tensile lap shear load obtained from the weld samples with the different volume 


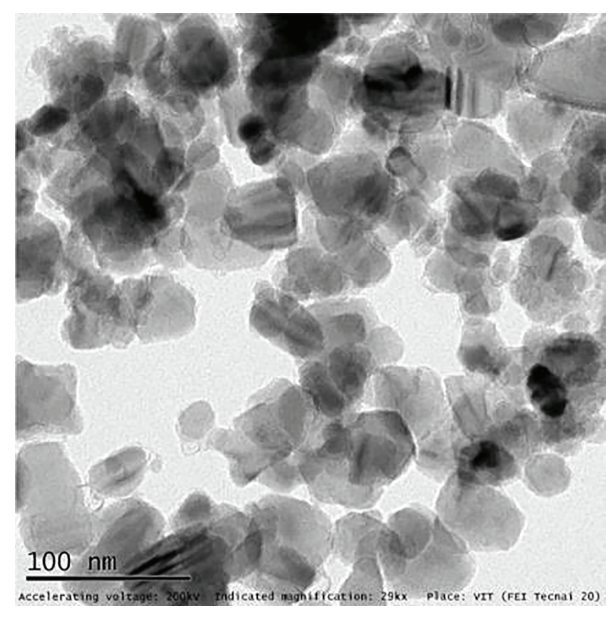

(a)

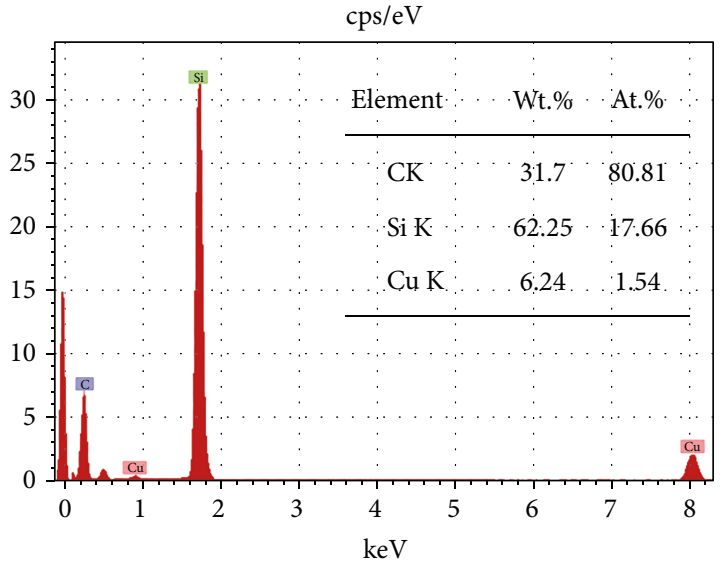

(b)

Figure 1: (a) TEM image and (b) EDS of as-received SiC nanoparticles.

TABle 3: Process parameters selected for FSSW.

\begin{tabular}{lcccc}
\hline Weld condition & Volume fraction (\%) & Tool rotation speed (rpm) & Dwell time (sec) & Shoulder plunge depth (mm) \\
\hline 1 & 0 & 1250 & 5 & 0.3 \\
2 & 14 & 1250 & 5 & 0.3 \\
3 & 22 & 1250 & 5 & 0.3 \\
4 & 29 & 1250 & 5 & 0.3 \\
\hline
\end{tabular}

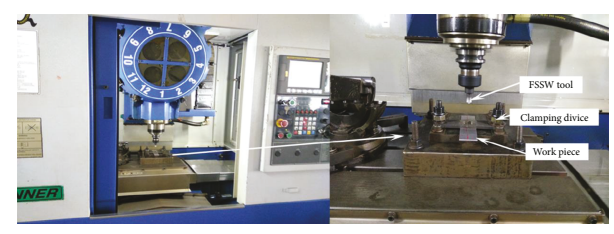

FIgure 2: Photograph of experimental setup in the CNC milling machine.

fraction of $\mathrm{SiC}$ nanoparticles is shown in Figures 6(a) and $6(b)$. It is evident that the reinforcement with the different volume fraction of $\mathrm{SiC}$ nanoparticles provides a significant variation in the shear strength of FSS weld samples. Frictional heat generation and reinforced particle attribute the grain size and dislocation density, which are the key factors that decide the tensile property of the material $[16,25,31]$. The maximum shear load of $2650.5 \mathrm{~N}$ was noticed in the weld joint prepared with the volume fraction of $29 \%$, which is $27.8 \%$ higher than the sample without $\mathrm{SiC}$. The shear load of the weld made with a volume fraction of $14 \%$ does not have significant influence as it is the same as samples without $\mathrm{SiC}$ particles. This behavior is in good agreement with the variation found in the hardness values of the weld joints. The shear mode of fracture was observed in all FSSW samples. Figure 6(c) shows the load-displacement curve of the welds. Significant increase in the toughness of the SiCreinforced weld is related to the concurrent increase of both elongation and the tensile shear strength. The sample with $29 \%$ volume fraction of $\mathrm{SiC}$ has the higher amount of elongation compared with the $\mathrm{SiC}$ free sample due to the effect of higher reinforcement of $\mathrm{SiC}$ nanoparticles.

3.3. Macro Examination. A variation of the cross-sectional macrostructure of FSS welded Al 6061-T6 is witnessed as the volume fraction of $\mathrm{SiC}$ nanoparticle varies from 0 to $29 \%$ as shown in Figures $7-10$. It is evident from the examinations that it facilitates the weld area around the keyhole. It shows typically bonded regions of weld cross section and indicates good appearance of the weld free from macro defects. The amount of plasticized material and continuous material flow behavior play a fundamental role to obtain the defect-free weld zone [32]. The vigorous stirring action of the rotating tool caused an interaction among the reinforced $\mathrm{SiC}$ nanoparticles during plunging and dwelling sequences and resulted a plasticized aluminum stir zone. It was also reported by $\mathrm{Su}$ et al. [33] in the past as an upward material flow with an anticlockwise spiral motion was observed in the stir zone formed by $\mathrm{Al}_{2} \mathrm{O}_{3}$ reinforced AA6061-T6.

The stir zone region associated with each cross section of the weld is observed differently. The larger stir zone area is noticed in the sample of higher reinforcement (29\% volume fraction of $\mathrm{SiC}$ ) as shown in Figure 10. When the volume fraction of $\mathrm{SiC}$ nanoparticles increases, the volume of the dark portion around and below the keyhole also increases and indicates deposition of nanoparticles in that specified regions. It is obvious that the tool movement and frictional heat depend on the operation parameters such as rotary tool 


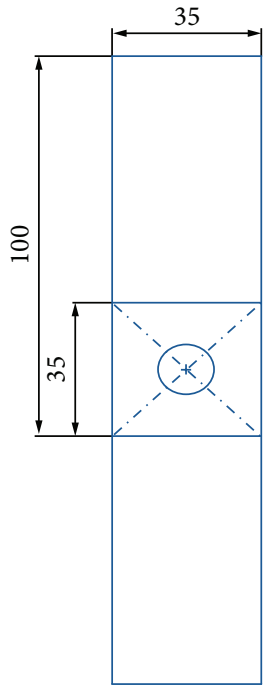

(a)


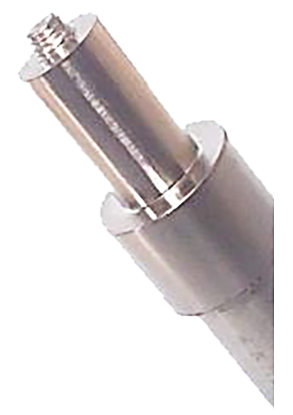

FIGURE 3: Dimensions of the (a) weld joint and (b) weld tool.

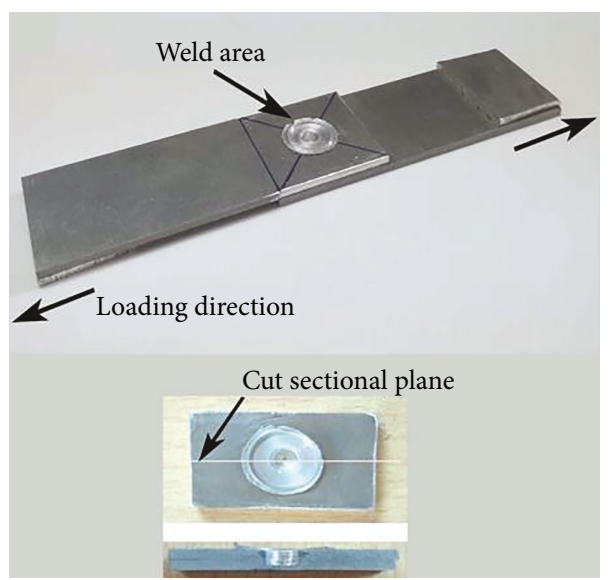

(a)

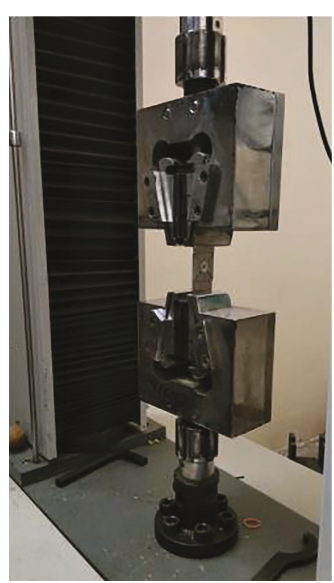

(b)

FIGURE 4: Photograph of the FSSW joint for (a) mechanical test and microstructural examination and (b) clamping of the welded sample in the universal testing machine.

speed, plunge depth, and dwell time. From the observed results, the selected set of process parameters is found adequate in order to fabricate a sound $\mathrm{Al} / \mathrm{SiC}$ composite joint.

3.4. Microstructural Study. The cross section of all the weld samples was observed through an optical microscope to investigate the material flow behavior after FSS welding close to the keyhole as shown in Figure 11. The dynamic recrystallization caused by the pin stirring and frictional heating is the factor for the material flow behavior and the formation of stir zone SZ [32]. The different material flow loci with different bonding and different width of the welded area are observed according to the volume fraction of $\mathrm{SiC}$ nanoparticles. It is remarkable that the SZ of the reinforced welds showed an onion ring structure with nonuniform alternating layers according to the volume fraction of $\mathrm{SiC}$ as shown in Figures 11(b) and 11(d). The three regions A, B, and C are observed in the images based on the presence of reinforced $\mathrm{SiC}$ nanoparticles near the keyhole. Region $\mathrm{A}$ is found having a little or even no distribution of particles. Region $\mathrm{B}$ is well developed by the good distribution of particles. But region $\mathrm{C}$ is somehow clustered without welldistributed $\mathrm{SiC}$ nanoparticles.

The SEM images of SZ of the weld samples without addition of $\mathrm{SiC}$ nanoparticles and with the addition of $\mathrm{SiC}$ nanoparticles of volume fractions $9 \%, 22 \%$, and $29 \%$, respectively, are presented in Figures 12(a)-12(d). It is observed that $\mathrm{SiC}$ was mixed with the base metal and located at the interior and middle of the stir zone from the keyhole and some being present at the bottom of the keyhole when particularly in the volume fraction of $14 \%$ and $22 \%$ of $\mathrm{SiC}$ as shown in Figures 12(b) and 12(c). However, the $\mathrm{SiC}$ particles are 


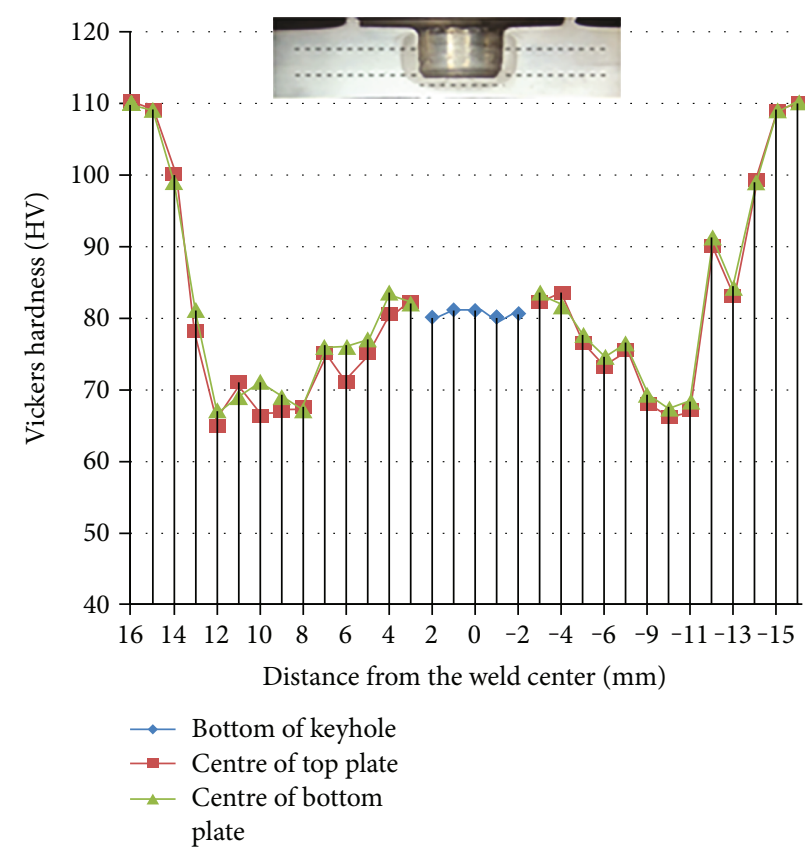

(a)

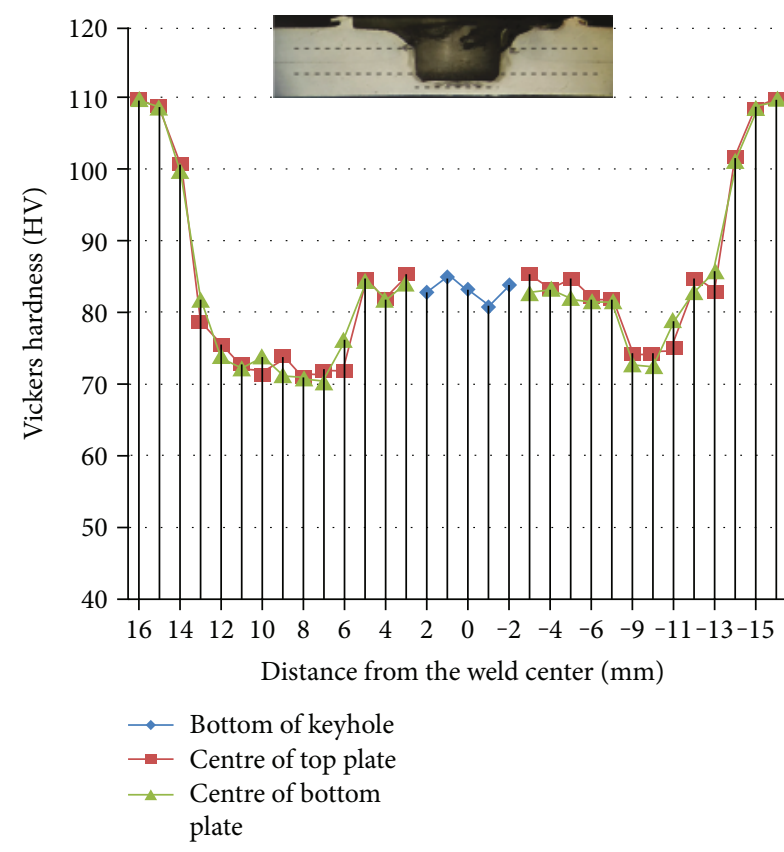

(c)

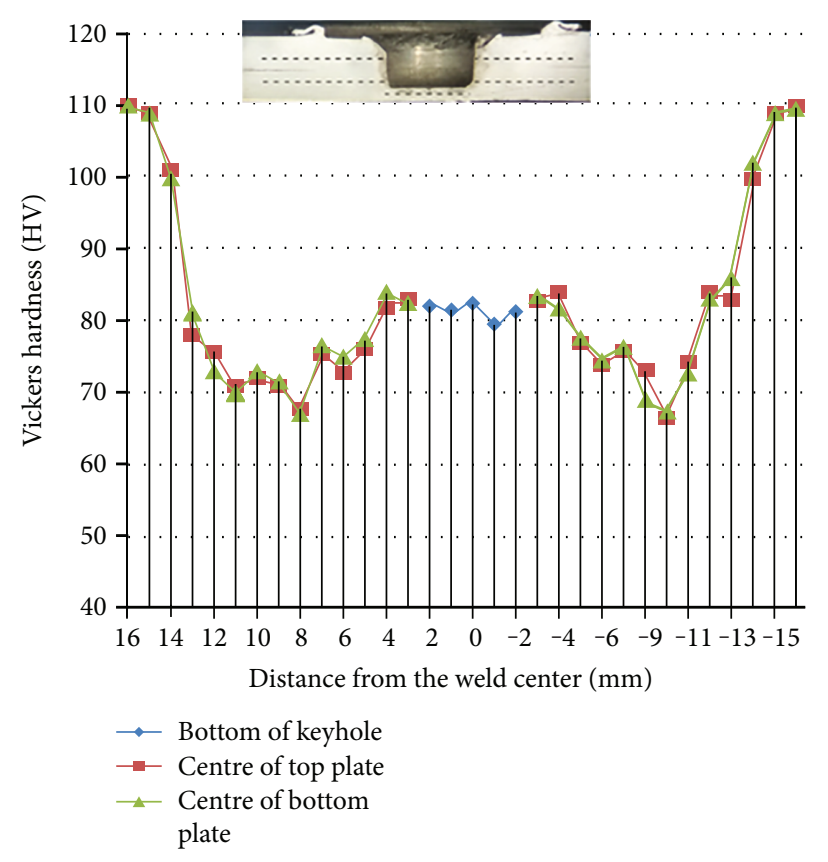

(b)

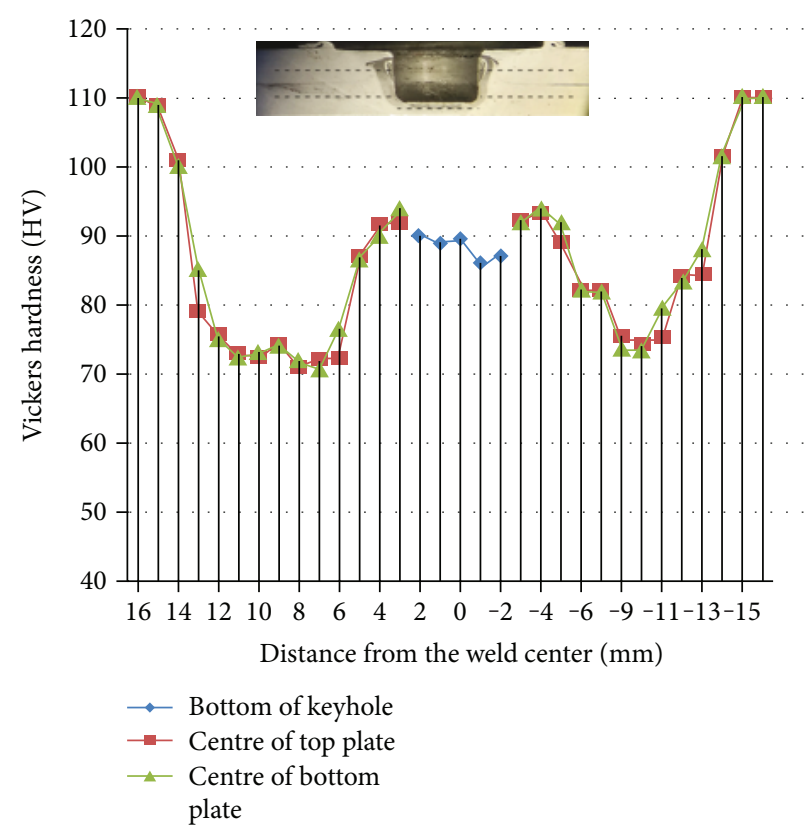

(d)

FIgUre 5: Hardness profile of the weld joints along top and bottom sheets (a) without SiC, (b) $14 \%$ volume fraction of SiC, (c) $22 \%$ volume fraction of $\mathrm{SiC}$, and (d) $29 \%$ volume fraction of $\mathrm{SiC}$.

also observed in the exterior of the stir zone area when the volume fraction is $29 \%$ as shown in Figure 12(d).

It is evident that the base metal and the $\mathrm{SiC}$ nanoparticles were compressed by the rotating tool during the plunging stage. When the bottom of the tool and the $\mathrm{SiC}$ particles come into contact, the $\mathrm{SiC}$ particles move to the side faces and then upwards forming a welded area [33]. When the volume fraction is $29 \%$, the width of the welded area increased to larger due to the high contact between the tool and the SiC particles and moreover due to the observed material flow behavior. Figure 13 shows the SEM images of the SZ of the welded samples for all the welding conditions, which indicates that the $\mathrm{SiC}$ particles uniformly dispersed into the $\mathrm{Al}$ matrix and with respect to the volume fraction of $\mathrm{SiC}$ particles.

The grains were refined well by the addition of $\mathrm{SiC}$ particles as seen in Figures 13(b) and 13(d), as compared with the samples without $\mathrm{SiC}$ shown in Figure 13(a). The presence of the $\mathrm{SiC}$-rich zone increases with the increase in the volume fraction of $\mathrm{SiC}$ particles. The satisfactory bonding along with 




(a)

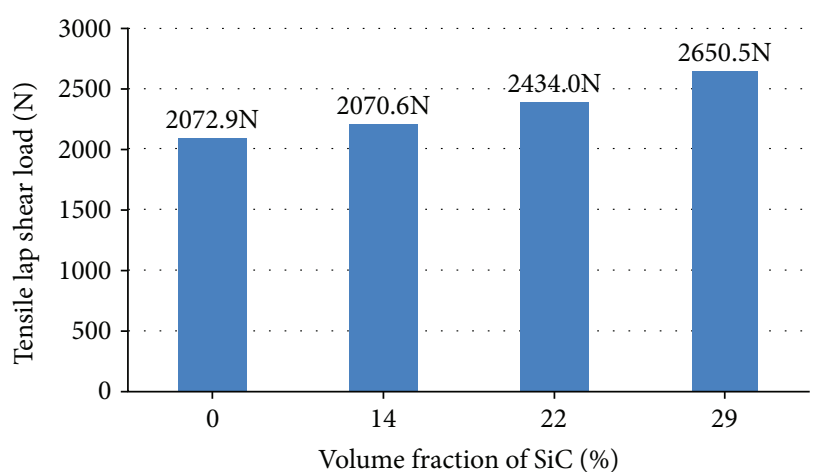

(b)

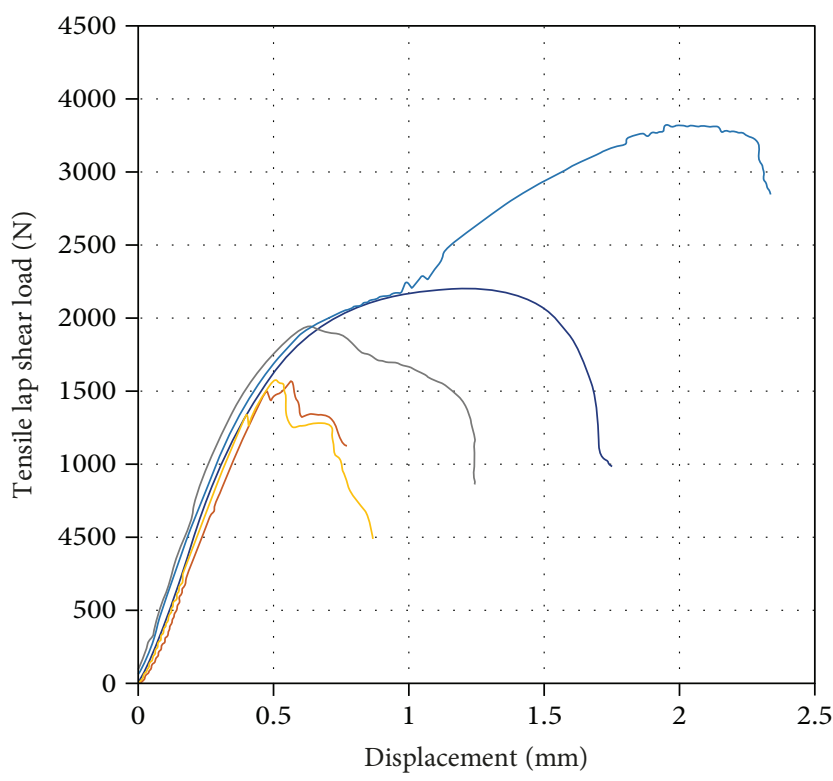

Volume fraction of $\mathrm{SiC}(\%)$

$\begin{array}{ll}-\quad 29 \% & -\quad \text { Without } \mathrm{SiC} \\ -\quad 14 \% & - \text { Base material }\end{array}$

(c)

Figure 6: (a) Photograph of specimens after the tensile lap shear test, (b) maximum tensile lap shear load against the volume fraction of SiC nanoparticles, and (c) load-displacement curve.

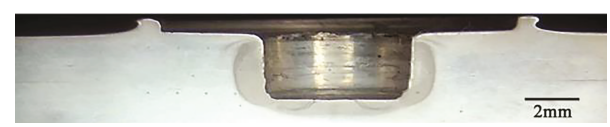

FIgURE 7: Macrostructure of the FSSW sample without SiC.

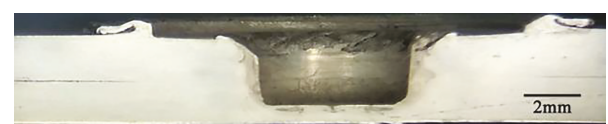

Figure 8: Macrostructure of the FSSW sample with 14\% volume fraction of $\mathrm{SiC}$.

the homogenous dispersion of $\mathrm{SiC}$ particles was observed in the high volume fraction of $22 \%$ and $29 \%$, respectively, as shown in Figures 13(c) and 13(d). Hence, the improved

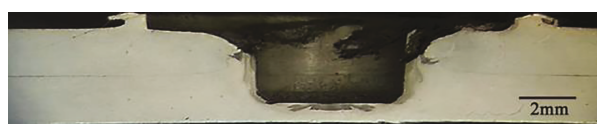

Figure 9: Macrostructure of the FSSW sample with 22\% volume fraction of SiC.

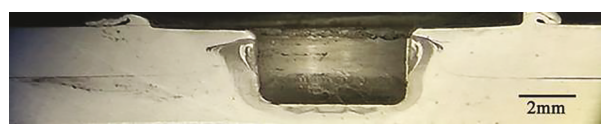

FIgURE 10: Macrostructure of the FSSW sample with 29\% volume fraction of SiC.

tensile strength is noticed due to the absence of a gap in the substrate/reinforcement interface. Conversely, the lower strength is noticed in $14 \% \mathrm{SiC}$ and $0 \% \mathrm{SiC}$ samples, which 


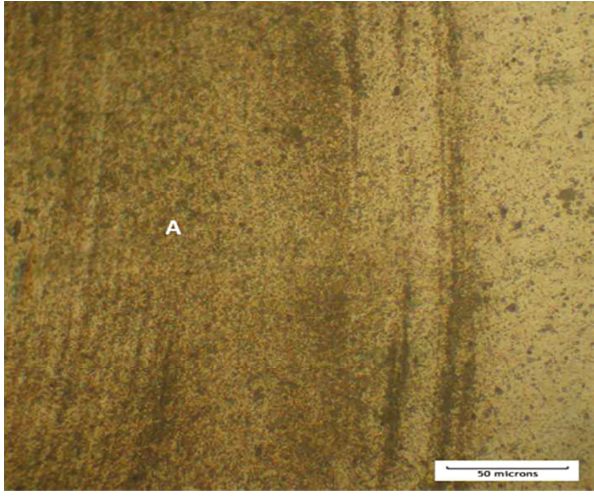

(a)

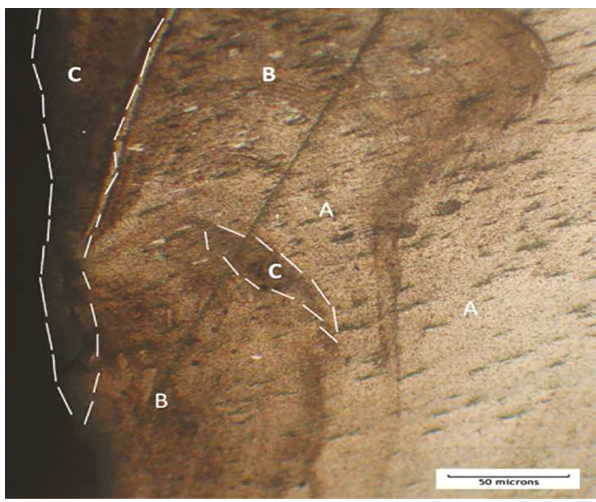

(c)



(b)



(d)

FIGURE 11: Optical micrographs showing the material flow behavior near the keyhole of the weld joints at mag. 100x (a) without SiC, (b) with $14 \%$ volume fraction of $\mathrm{SiC}$, (c) with $22 \%$ volume fraction of $\mathrm{SiC}$, and (d) with $29 \%$ volume fraction of $\mathrm{SiC}$.

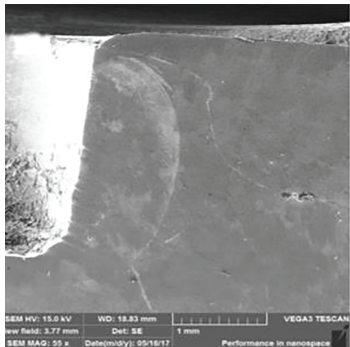

(a)



(b)



(c)

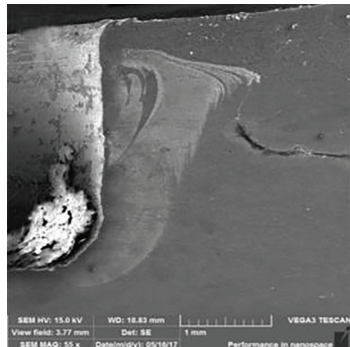

(d)

FIGURE 12: SEM cross section of welded samples (a) without $\mathrm{SiC}$, (b) with $14 \%$ volume fraction of $\mathrm{SiC}$, (c) with $22 \%$ volume fraction of $\mathrm{SiC}$, and (d) with $29 \%$ volume fraction of SiC.

could be attributed by the larger grain sizes associated and mediocre dispersion of the filler. Figure 14 shows the result from EDS analysis of the arrow-marked portion of the sample with $29 \% \mathrm{SiC}$ shown in Figure 13(d). The result confirmed the presence of $\mathrm{SiC}$ particles in the weld area.

3.5. Study of Fracture Surfaces. Interfacial fracture, shear fracture, and plug fracture are the different kinds of failure modes addressed in the literatures $[19,20]$. The fracture surfaces of samples after the lap shear test were studied to understand the mechanism of the shear fracture mode of failure in the lap section. The various views (top and bottom of the upper sheet and top of bottom sheet) of fracture surfaces at different welding conditions are shown in Figure 15. A circular pattern was observed at the surface of the top sheet almost in the same diameter as the shoulder. The weld keyhole is seen in all the samples in the center of the upper sheet and penetrates through the lower sheet. The crack was initiated in the partial bonding region because of several nucleation sites, and the crack propagated entirely through the bonded area. In shear fracture, the material got sheared off at the circumferential portion of the keyhole due to tearing action as reported in [20]. 


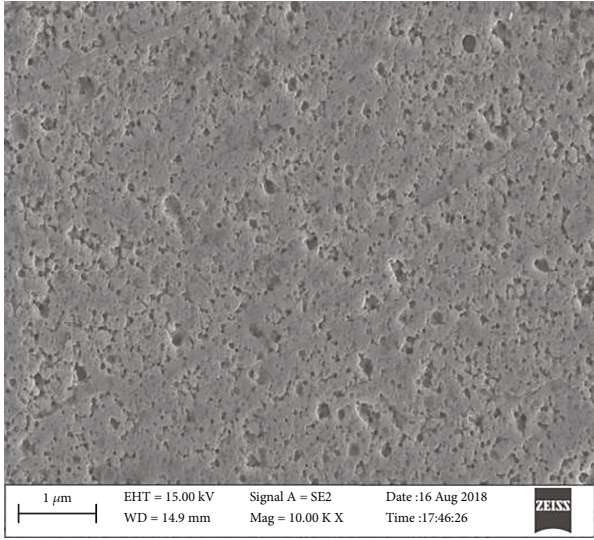

(a)

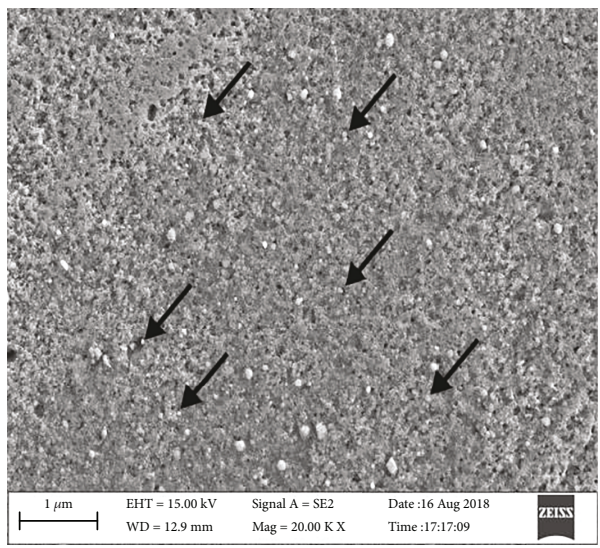

(c)

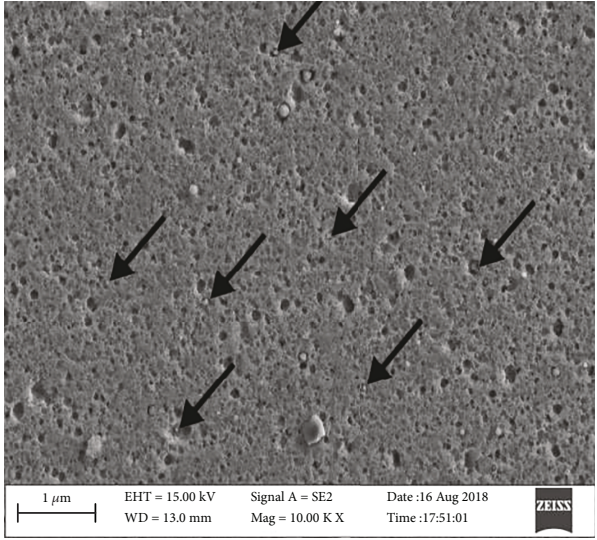

(b)

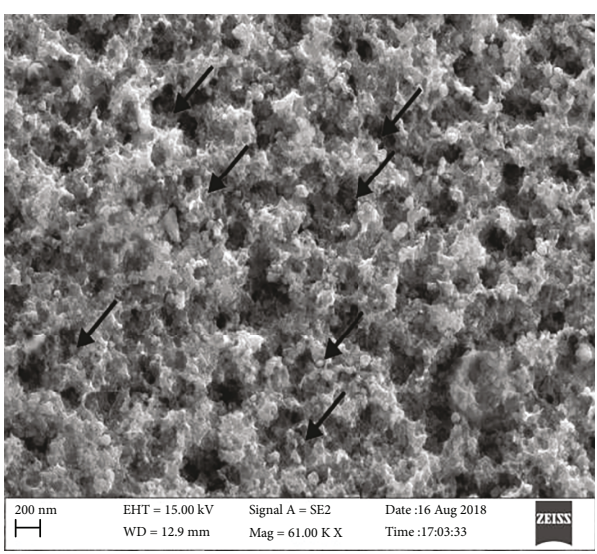

(d)

Figure 13: FESEM images showing (arrow marks) the distribution of SiC particles in stir zones of the welded samples (a) without SiC, (b) with $14 \%$ volume fraction of $\mathrm{SiC}$, (c) with $22 \%$ volume fraction of $\mathrm{SiC}$, and (d) with $29 \%$ volume fraction of $\mathrm{SiC}$.

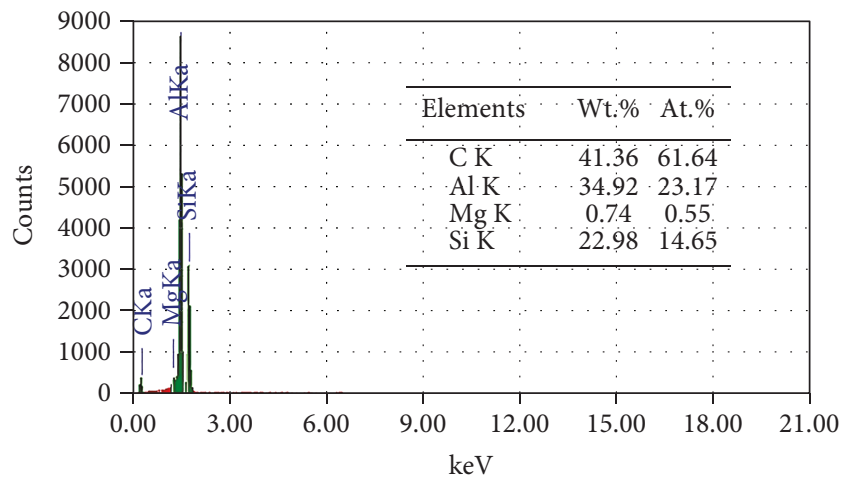

FIGURE 14: EDS analytical result for the SiC-rich area in Figure 13(d).

Figures 16 and 17 show FESEM images of the fractured lower sheet of the lap shear specimens without $\mathrm{SiC}$ and with $29 \%$ SiC nanoparticles, respectively. It is observed that the fracture surfaces consist of finer dimples due to the presence of nanoparticles that led the specimen more ductile [27]. It is also observed from Figure 6 that the significant improvement in the elongation is noticed in SiC-reinforced welds, especially at high reinforcement of $\mathrm{SiC}$, which regarded as a good accordance with ductility. It is worth noting the presence of large pores on the fracture planes in SiC-free samples. In addition, with the fracture surfaces in the same direction, the stretched-out dimples can cause the shear fracture as published in [19].

\section{Conclusions}

Friction stir spot-welding of AA6061-T6 alloy was carried out with and without the addition of $\mathrm{SiC}$ nanoparticles. The volume fractions of $14 \%, 22 \%$, and $29 \%$ of SiC were chosen to compact the specimens. The FSS welding was performed with a hardened $\mathrm{H} 13$ steel weld tool in a CNC vertical machining center. The tests for mechanical properties and macro and micro examinations were carried out, and the following conclusions are drawn:

(1) The hardness of the stir zone increases with an increase in the volume fraction of $\mathrm{SiC}$ nanoparticles. The significant increase in hardness was observed beyond $14 \%$ volume fraction of $\mathrm{SiC}$. The highest value of hardness in the stir zone was observed as $93 \mathrm{HZ}$ with the volume fraction of $29 \%$ SiC. All the weld samples exhibited similar "W" shape hardness profile 




FIGURE 15: Photograph of fracture surfaces at different welding conditions.

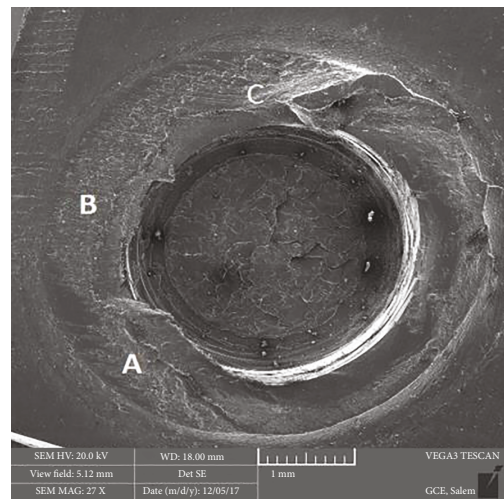

(a)

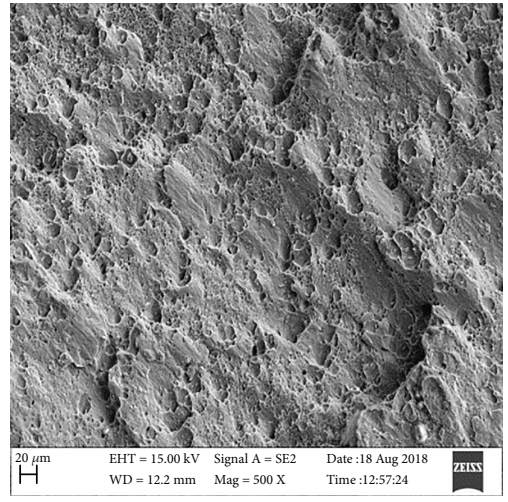

(c)

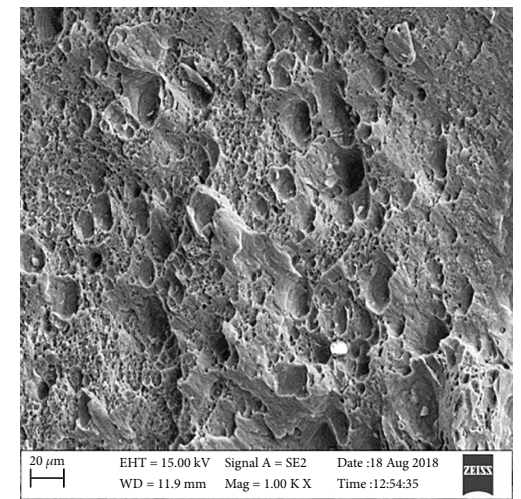

(b)

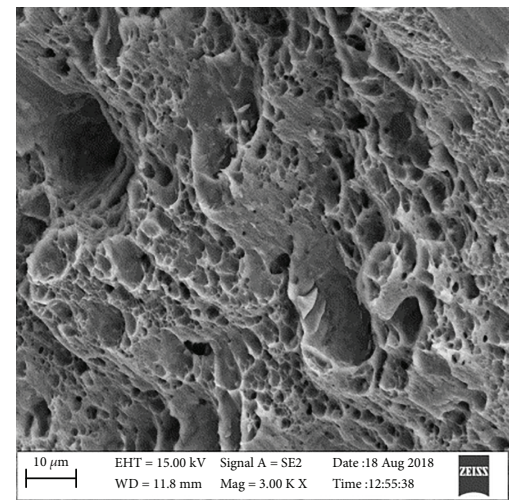

(d)

FIGURE 16: SEM images of the fracture surface of the tensile shear sample of the SiC-free joint: (a) fracture surface of the lower sheet; (b-d) magnified views of points A, B, and C in (a), respectively. 


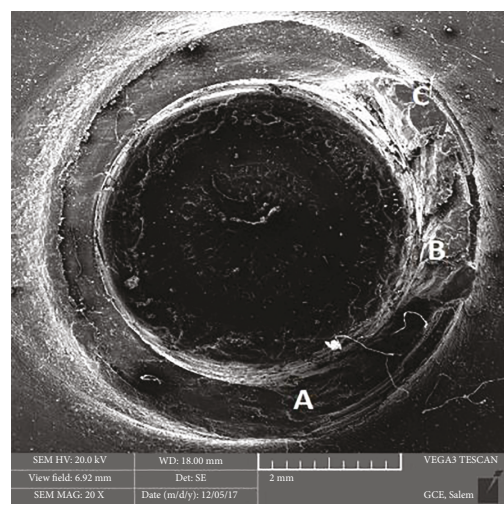

(a)

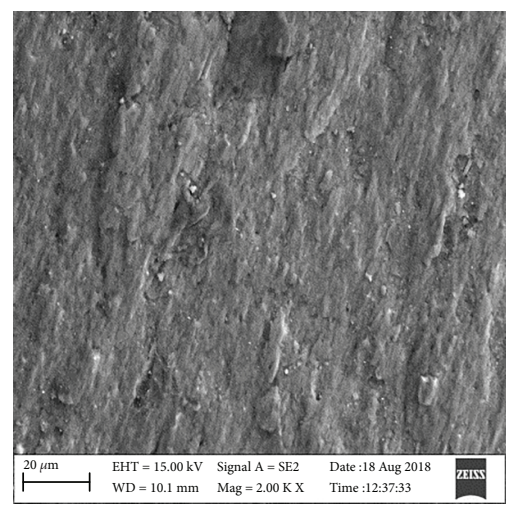

(c)

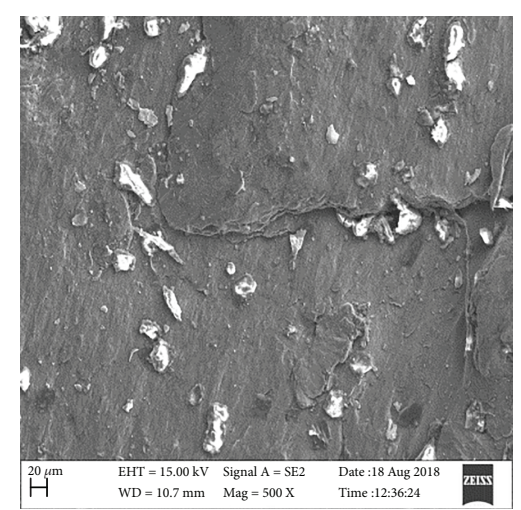

(b)

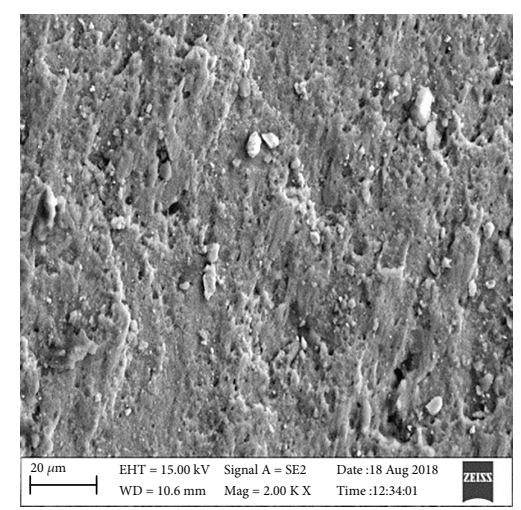

(d)

Figure 17: SEM images of the fracture surface of the tensile shear sample of $29 \%$ volume fraction of the SiC joint: (a) fracture surface of the lower sheet; (b-d) magnified views of points A, B, and C in (a), respectively.

(2) There was an increase in tensile lap shear load with the increasing volume fraction of $\mathrm{SiC}$ nanoparticles, and the maximum shear load of $2650.5 \mathrm{~N}$ was obtained in the weld joint made with the volume fraction of $29 \%$. This behavior is found to be in good agreement with the variation found in the hardness values of the weld joints

(3) Shear mode of fracture was observed in all the FSS weld samples

(4) The different material flow and three different weld regions in the weld area were observed according to the addition of $\mathrm{SiC}$ nanoparticles

(5) The grain growth was prevented in the stir zone by the addition of $\mathrm{SiC}$ nanoparticles

\section{Conflicts of Interest}

The authors declare that they have no conflicts of interest.

\section{Acknowledgments}

Authors would like to thank CERVIE, UCSI University, for financially supporting the publication of the article.

\section{References}

[1] J. Hirsch, "Aluminium in innovative light-weight car design," Materials Transactions, vol. 52, no. 5, pp. 818-824, 2011.

[2] D. Carle and G. Blount, "The suitability of aluminium as an alternative material for car bodies," Materials and Design, vol. 20, no. 5, pp. 267-272, 1999.

[3] W. M. Thomas, E. D. Nicholas, J. C. Needham, M. G. Murch, P. Temple-Smith, and C. J. Dawes, International Patent Application PCT/GB92/02203 and GB Patent Application 9125978, vol. 8, UK Patent Office, London, 1991.

[4] M. Awang and V. H. Mucino, "Energy generation during friction stir spot welding (FSSW) of Al 6061-T6 plates," Materials and Manufacturing Processes, vol. 25, no. 1-3, pp. 167-174, 2010.

[5] H. Badarinarayan, Q. Yang, and S. Zhu, "Effect of tool geometry on static strength of friction stir spot-welded aluminum alloy," International Journal of Machine Tools and Manufacture, vol. 49, no. 2, pp. 142-148, 2009.

[6] Y. Uematsu and K. Tokaji, "Comparison of fatigue behaviour between resistance spot and friction stir spot welded aluminium alloy sheets," Science and Technology of Welding and Joining, vol. 14, no. 1, pp. 62-71, 2013.

[7] P. Briskham, N. J. Blundell, L. Han, R. Hewitt, K. Young, and D. Boomer, "Comparison of self-pierce riveting, resistance spot welding and spot friction joining for aluminium automotive sheet," in SAE World Congress \& Exhibition, USA, April 2006. 
[8] Z. Shen, X. Yang, S. Yang, Z. Zhang, and Y. Yin, "Microstructure and mechanical properties of friction spot welded 6061-T4 aluminum alloy," Materials and Design, vol. 54, pp. 766-778, 2014.

[9] S. H. Chowdhury, D. L. Chen, S. D. Bhole, X. Cao, and P. Wanjara, "Lap shear strength and fatigue life of friction stir spot welded AZ31 magnesium and 5754 aluminum alloys," Materials Science and Engineering: A, vol. 556, pp. 500-509, 2012.

[10] H. M. Rao, J. B. Jordon, M. E. Barkey, Y. B. Guo, X. Su, and H. Badarinarayan, "Influence of structural integrity on fatigue behavior of friction stir spot welded AZ31 Mg alloy," Materials Science and Engineering A, vol. 564, pp. 369-380, 2013.

[11] Y. Uematsu, T. Kakiuchi, Y. Tozaki, and H. Kojin, "Comparative study of fatigue behaviour in dissimilar Al alloy/steel and $\mathrm{Mg}$ alloy/steel friction stir spot welds fabricated by scroll grooved tool without probe," Science and Technology of Welding and Joining, vol. 17, no. 5, pp. 348-356, 2013.

[12] J. Rodelas, R. S. Mishra, G. Hilmas, and W. Yuan, "Mechanical evaluation of friction stir spot welded advanced high strength steels," Friction Stir Welding and Processing, vol. 5, pp. 171179, 2009.

[13] Y. Hovanski, M. L. Santella, and G. J. Grant, "Friction stir spot welding of hot-stamped boron steel," Scripta Materialia, vol. 57, no. 9, pp. 873-876, 2007.

[14] J. Y. Cao, M. Wang, L. Kong, and L. J. Guo, "Hook formation and mechanical properties of friction spot welding in alloy 6061-T6," Journal of Materials Processing Technology, vol. 230, pp. 254-262, 2016.

[15] R. Karthikeyan and V. Balasubramanian, "Optimisation and sensitivity analysis of friction stir spot-welding process parameters for joining AA6061 aluminum alloy," International Journal of Manufacturing Research, vol. 7, no. 3, pp. 257-272, 2012.

[16] Z. M. Su, Q. H. Qiu, and P. C. Lin, "Design of friction stir spot welding tools by using a novel thermal-mechanical approach," Materials, vol. 9, no. 8, 2016.

[17] S. H. Lee, D. M. Lee, and K. S. Lee, "Process optimisation and microstructural evolution of friction stir spot-welded Al6061 joints," Materials Science and Technology, vol. 33, no. 6, pp. 719-730, 2016.

[18] S. Venukumar, B. Baby, S. Muthukumaran, and S. V. Kailas, "Microstructural and mechanical properties of walking friction stir spot welded AA6061-T6 sheets," Procedia Materials Science, vol. 6, pp. 656-665, 2014.

[19] S. Venukumar, S. G. Yalagi, S. Muthukumaran, and S. V. Kailas, "Static shear strength and fatigue life of refill friction stir spot welded AA 6061-T6 sheets," Science and Technology of Welding and Joining, vol. 19, no. 3, pp. 214-223, 2013.

[20] S. Venukumar, S. Yalagi, and S. Muthukumaran, "Comparison of microstructure and mechanical properties of conventional and refilled friction stir spot welds in AA6061-T6 using filler plate," Transactions of Nonferrous Metals Society of China, vol. 23, no. 10, pp. 2833-2842, 2013.

[21] M. Bahrami, K. Dehghani, and M. K. Besharati Givi, "A novel approach to develop aluminum matrix nano-composite employing friction stir welding technique," Materials and Design, vol. 53, pp. 217-225, 2014.

[22] M. Bahrami, M. K. Besharati Givi, K. Dehghani, and N. Parvin, "On the role of pin geometry in microstructure and mechanical properties of AA7075/SiC nano-composite fabricated by friction stir welding technique," Materials and Design, vol. 53, pp. 519-527, 2014.

[23] M. Bahrami, N. Helmi, K. Dehghani, and M. K. Besharati Givi, "Exploring the effects of $\mathrm{SiC}$ reinforcement incorporation on mechanical properties of friction stir welded 7075 aluminum alloy: fatigue life, impact energy, tensile strength," Materials Science and Engineering: A, vol. 595, pp. 173-178, 2014.

[24] M. Barmouz, P. Asadi, M. K. Besharati Givi, and M. Taherishargh, "Investigation of mechanical properties of $\mathrm{Cu} / \mathrm{SiC}$ composite fabricated by FSP: effect of SiC particles' size and volume fraction," Materials Science and Engineering: A, vol. 528, no. 3, pp. 1740-1749, 2011.

[25] R. S. Mishra and Z. Y. Ma, "Friction stir welding and processing," Materials Science and Engineering: R: Reports, vol. 50, no. 1-2, pp. 1-78, 2005.

[26] M. Paidar and M. L. Sarab, "Friction stir spot welding of 2024T3 aluminum alloy with $\mathrm{SiC}$ nanoparticles," Journal of Mechanical Science and Technology, vol. 30, no. 1, pp. 365370, 2016.

[27] S. F. Tebyani and K. Dehghani, "Effects of SiC nanopowders on the mechanical properties and microstructure of interstitial free steel joined via friction stir spot welding," Materials \& Design, vol. 90, pp. 660-668, 2016.

[28] N. Elango and A. A. M. Faudzi, "A review article: investigations on soft materials for soft robot manipulations," The International Journal of Advanced Manufacturing Technology, vol. 80, no. 5-8, pp. 1027-1037, 2015.

[29] N. Elango, N. S. Gupta, Y. Lih Jiun, and A. Golshahr, "The effect of high loaded multiwall carbon nanotubes in natural rubber and their nonlinear material constants," Journal of Nanomaterials, vol. 2017, Article ID 6193961, 15 pages, 2017.

[30] M. Barmouz, M. K. Besharati Givi, and J. Seyfi, "On the role of processing parameters in producing $\mathrm{Cu} / \mathrm{SiC}$ metal matrix composites via friction stir processing: investigating microstructure, microhardness, wear and tensile behavior," Materials Characterization, vol. 62, no. 1, pp. 108-117, 2011.

[31] Y. F. Sun and H. Fujii, "The effect of SiC particles on the microstructure and mechanical properties of friction stir welded pure copper joints," Materials Science and Engineering: A, vol. 528, no. 16-17, pp. 5470-5475, 2011.

[32] R. Sathiskumar, N. Murugan, I. Dinaharan, and S. J. Vijay, "Characterization of boron carbide particulate reinforced in situ copper surface composites synthesized using friction stir processing," Materials Characterization, vol. 84, pp. 16-27, 2013.

[33] P. Su, A. Gerlich, T. H. North, and G. J. Bendzsak, "Material flow during friction stir spot welding," Science and Technology of Welding and Joining, vol. 11, no. 1, pp. 61-71, 2013. 


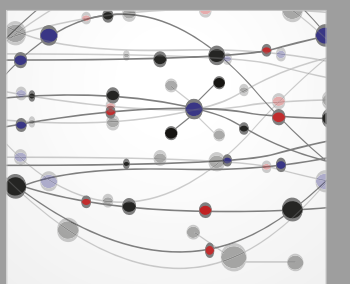

The Scientific World Journal
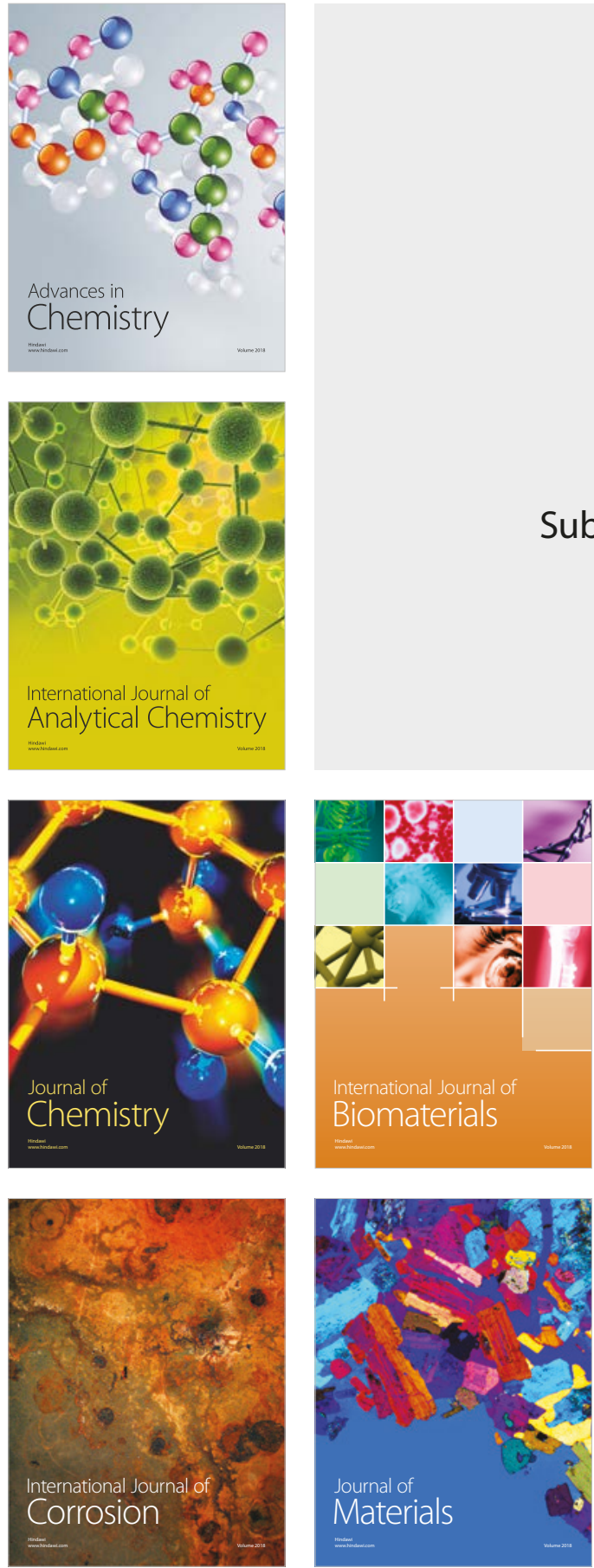

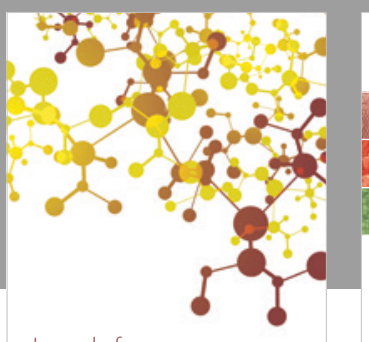

Journal of

Applied Chemistry


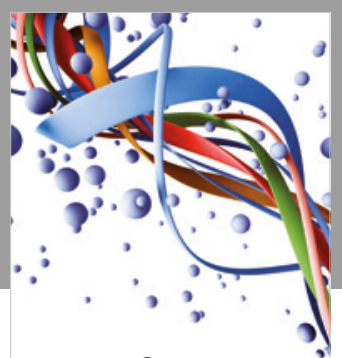

Scientifica

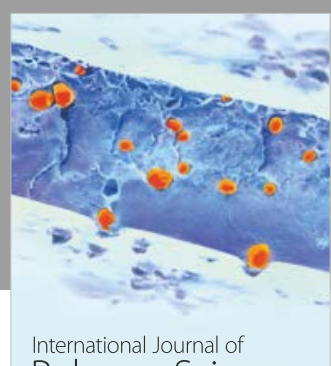

Polymer Science



Physical Chemistry
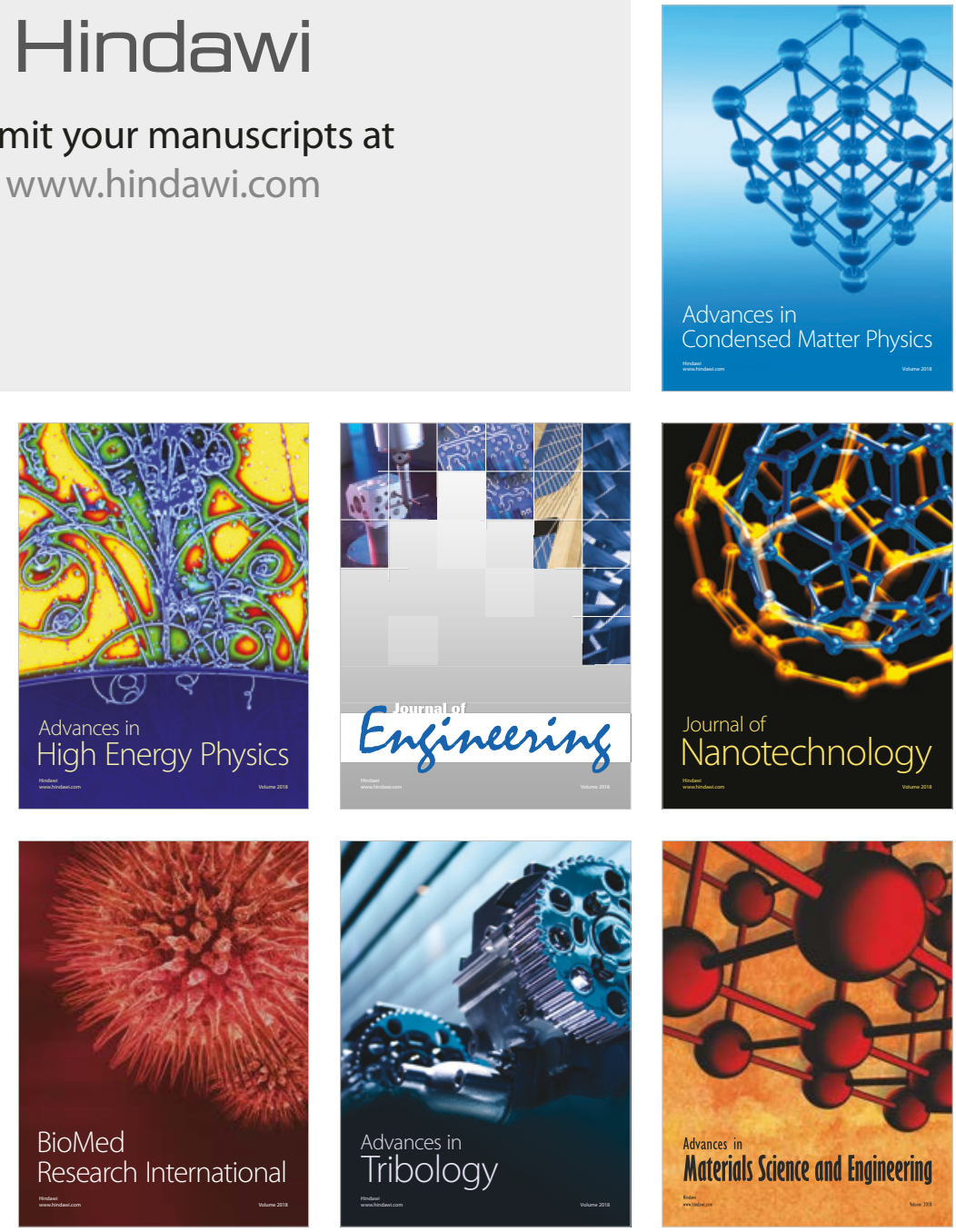